\title{
Markov Chain Model in Measuring Brand Switching of Cooking Oil
}

\author{
Muhammad Dharma Tuah Putra Nasution ${ }^{\text {* }}$, Nashrudin Setiawan', Yossie Rossanty ${ }^{1}$, \\ Irawan $^{1}$,Solly Aryza Lubis ${ }^{2}$ \\ \{dharma_nasution@dosen.pancabudi.ac.id*\}
}

${ }^{1}$ Faculty of Social Science, Universitas Pembangunan Panca Budi, Medan, Indonesia ${ }^{2}$ Faculty of Science and Technology, Universitas Pembangunan Panca Budi, Medan, Indonesia

\begin{abstract}
This research aims to explore the brand switching of cooking oil to other brands made by the purchasers, especially homemakers. Another goal is to analyze the various considerations of homemakers when choosing and deciding to switch to another brand. The authors also explain how the market share of cooking oil brands in the present and future and use descriptive analysis by presenting the results of information from homemakers as consumers of various brands of cooking oil. The data collected in this research are primary and secondary data. The result of this study is that consumers who switched to Tropical and Sania were more than consumers who moved from both brands. Meanwhile, Sunco consumers are the most consumers switching to other brands. The most popular brand of cooking oil is Bimoli. The next sequence is Tropical and Sania. Most consumers choose Bimoli cooking oil because this oil is classified as a famous product, easily obtained, and the habits of the family. Unlike Tropical, most consumers choose because of the economical price. For Sania, consumers who choose this brand is due to nutritional value information and is classified as a famous brand. The results also show that market share is still dominated by Bimoli, followed by Tropical and Sania. Bimoli's market share growth is predicted to grow by 2.4 percent. A significant market share increase occurred in Sania, while there was a decrease in market share for Tropical.
\end{abstract}

Keywords: Markov Chain, Brand Equity, Brand Switching, Market Share, External Factor, Internal Factor.

\section{Introduction}

Products and brands have to fight competition. A reason is a rapid advancement of technology and the more creative marketing concepts and promotional strategies launched by all companies. The market will become more competitive and more crowded. Brands competition is circulating in the market even more fierce. In addition to current promotion, the market has now entered the digital era. All forms of promotion have entered and played in the digital realm.It is forming its market with many opportunities ready to be utilized for whom are ready. In the end, there are only one or two consumer product brands selected in one product category. For instance, many consumers like and select one of the brands in the market. Many factors can cause consumers unsatisfied with a brand of product. These factors may come from the product itself, and it can come from the outside. Many products features do not match what is being promoted. It is found in the term, "Over promise under deliver." A brand provided the high expectation to customers when products promoted should be careful with risks that may be faced later if the product is unable to fulfill the customer's expectation. Conversely, if the promotion provided is reasonable and attractive, consumers will be more satisfied if the product can fulfill the consumers' expectations. Consumers will be more tolerant of a brand because previously the brand does not over-promise. Consumers want the 
excellent products at reasonable prices. However, if the product itself cannot be found anywhere, it causes consumers' unsatisfied and then switches to another brand. Another cause consumers are unsatisfied with a brand may come from external factors. Some causes come from outside the brand of a product to make consumers no longer feel satisfied with the current offer. There are also factors that can influence consumers to choose a particular product brand than others. Consumers will choose a particular product because there are people nearby or others are trusted who using the same brand. Consumers tend to look for referrals from people they respect. They do not just believe in any ads or promotions that are served. Consumers will choose a particular brand if they are loyal to a brand. Consumers tend to try other brands for a similar product; unfortunately, they do not find a brand suited their expectation. Many types of products or brands do not only rely on quality but also depends on the suitability of consumer conditions and situations. In addition, consumer behavior can be affected by the price sensitivity of a product. Price sensitivity is also known as the price elasticity of existing demand. It means how far the sales of a product can be affected by the price. The cooking oil brands should be more careful in maintaining price sensitivity due to consumers are now quickly switching to other brands. A brand may already be active in consumers minds, and consumers become accustomed purchasing the brand. However, if one day customers realize that the product price is unworthy the quality, then the brands will lose their customers.

Most people think to obtain lower prices causes consumers sensitivity to obtain cut-price or discount of products. Apparently, the solution is not the case. Lowering prices cannot always solve problems; it may even create new problems. When customers are faced with multiple choices for the same product, they often return to brands they have liked for a long time. The more options offered, the harder it is to make a decision. Consumers will return to familiar products rather than taking a risk to a new and unknown product. Consumers are more responsive to brands, much less there is an emotional attachment, than with lower prices. Brands have an essential role in maintaining customer certainty. A brand is a prestigious asset. A prestigious brand has high and solid equity. Products with strong brand equity will form a solid brand platform and be able to develop a brand presence in any competition for long periods time. Several brands and products compete in the market and consumers have a variety of brand choices and alternatives to fulfill their needs. The cooking oil brands on the market have features that are difficult to distinguish. For example, Bimoli, Sania, Tropical, Sunco, Kunci Mas, Filma, and others. The Frontier Consulting Group reported that the cooking oil brands included in the Top Brand of 2017 are in the following table.

Table 1. Top brand phase 12017 , category: food \& drink.

\begin{tabular}{lll} 
Brand & TBI & TOP \\
\hline Bimoli & $43.7 \%$ & TOP \\
\hline Tropical & $14.4 \%$ & TOP \\
\hline Sania & $12.3 \%$ & TOP \\
\hline Filma & $12.0 \%$ & TOP \\
\hline Sunco & $5.1 \%$ & TOP \\
\hline Fortune & $3.1 \%$ & TOP \\
\hline
\end{tabular}




\section{Literature Review}

\subsection{Factors Affecting Consumer Behavior}

In marketing literature, the behavior concept is related to consumer behavior. Behavior is what consumers show to search, purchase, use, evaluate, and spend products and services that consumers expect can satisfy their needs. (Engel,. et.all, 2000) explain that consumer behavior is direct actions involved in obtaining, consuming, and disposing of a product or service, including the decision process that precedes and follows specific actions. Consumer behavior focuses on activities related to individual consumption. It means that consumer behavior is related to the reasons and pressures that affect the selection, purchase, use, and rejection of goods and services for satisfying personal needs and desires. This action is a part of the consumer purchase decision process.

\subsection{Consumer Purchase Decision Process}

Consumer Purchase decisions are the result of an interrelated and complex relationship between internal factors of culture, social, personal, and psychological. (Kotler, 2001) asserted that several factors influence consumer purchase decisions:

1. Cultural factors consist of culture, subculture, and social class.

2. Social factors consist of a reference group, family, role, and status.

3. Personal factors consist of age, occupation, economic situation, lifestyle, and personality. 4. Psychological factors consist of knowledge, motivation, beliefs, and attitudes.

Consumers purchase decisions through several stages, recognition of needs, searching information, purchase decision and post-purchase behavior.

\subsection{Market Share}

Market Share interpreted as part of a market that controlled by a company, or a company's sales percentage of the total sales compared to the most significant competitors with a specific time and place.

\subsection{Brand Equity}

A brand is a name or symbol provided by the manufacturer to differentiates the goods or services produced by other manufacturers. A Brand Equity under is a set of Brand Assets and Liabilities that relate to a brand and symbol provided by a product or service to the consumers (Aaker, 1997). Brand equity has five categories:

1.Brand Loyalty

2.Brand Awareness

3.Brand Association

4.Perceived Quality

5.Other Proprietary Brand Asset

Brand loyalty is the core of brand equity. A product may have good brand awareness, good quality, and the significant brand association, but not necessarily brand loyalty. In contrast, products that have brand loyalty can be assured of high brand awareness, good quality, and a well-known association (Aaker, 1997). 


\subsection{Brand Switching}

Brand switching is the activity of a user who switches a brand from one product to another for some reason. It is part of brand loyalty where a loyal user uses a particular brand. Brand loyalty is a measure of the user's connection to a brand. Brand loyalty is a market condition with a little growth rate but a very tight level of competition today. The existence of the user is very loyal to the brand of a product is needed for companies to survive and retention of these users often become a much more efficient strategy than attracting new users to consume their products (Durianto and Sitinjak., 2001).

\subsection{Markov Chain}

Markov Chain Analysis is a method that studies the properties of a variable in the present based on its past traits in an attempt to estimate the properties of those variables in the future (Siagian, 2006). Markov's analysis provides probabilistic information that can be used to assist decision making, and this analysis is not an optimization technique but a descriptive technique.

\subsection{Conceptual Framework}

Consumer behavior describes how consumers make purchase decisions and how they use and manage the purchase of goods or services. It is based on their perceptions that are influenced by internal factors and external factors. Internal factors are culture (habit), social factors (such as reference group, family, status), personal factors (such as age, occupation, financial situation), and psychological factors (such as motivation and belief). The external factor is a marketing stimulus consisting of product (such as brand, packaging, label, color, smell, taste), price (discount), and promotion (advertisement). Both factors are internal factors, and external factors will shape consumer perceptions that will affect consumers in deciding to purchase cooking oil products.

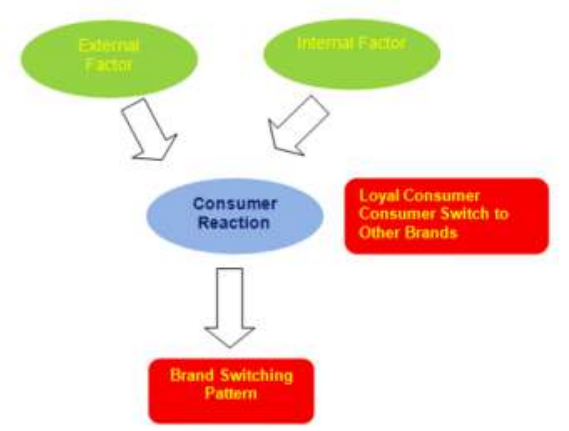

Fig. 1. Brand Switching Framework.

\section{Methodology}

\subsection{Research Approach}

This research is descriptive research, intended for exploration and clarification of a phenomenon or social reality, by describing some variables concerning the problem and the unit under investigation. It is not to question the network of relationships between variables that exist do not mean to attract a generation that explains antecedent variables that cause a 
symptom or social reality. The descriptive study does not use and conduct hypothesis testing in the management and data analysis. It is usually using descriptive statistics. The object of research is homemakers without age and professional restrictions. The product brands examined are cooking oil packaging under the brand Bimoli, Sania, Sunco, Tropical, Filma, and other brands (Fortune and Kunci Mas).

\subsection{Definitions and Operational Variables}

Markov Chain analysis is a method that studies the properties of a variable in the present based on the past evidence in an attempt to assess the properties of those variables in the future.

Brand switching is the activity of a user who switches a brand from one product to another for any reason. Market share is a part of a market dominated by a company or a percentage of a company's sales of the total sales of its most significant competitors at a specific time and place.

\subsection{Population and Sample}

Total Population (N) is 507,205 households in Medan. The method of measurement conducted in this study is probability sampling. It uses simple random sample proportionally with the intention that the number of samples by the number of population, where the sample size of each district taken proportionally. This study takes 146 samples.

\subsection{Data Analysis Method}

The purpose of data analysis is to explain the pattern of brand switching of cooking oil from one brand to another made by homemakers. It is analyzed descriptively by making pattern switch of the brand from one brand of cooking oil to other cooking oil brand. As for the magnitude of transition opportunities analyzed by using the equation:

$P i j=\frac{n i j(t)}{n i(t)}$

Where:

$\mathrm{Pij}=$ transition probability (switch from brand $\mathrm{i}$ to brand $\mathrm{j}$ )

$n i j(t)=$ number of cooking oil consumers who move from brand $i$ to brand $j$ in period $t$

ni $(t)=$ number of brand cooking oil consumers $i$ at the beginning of period $t$

Data analysis is to analyze what the homemakers consider in choosing, and switching the cooking oil brands that analyzed descriptively. It is performed by tabulating the data or brand information of cooking oil consumed by calculating the proportion. It is determined by the percentage comparison of the number of consumers of certain cooking oil to the number of respondents obtained from the questionnaires that have been answered by the consumers. The objective is to analyze the market share of cooking oil brands in the future that analyzed descriptive using the equation:

$\mathrm{MK}_{(\mathrm{t})}=\mathrm{MK}_{(\mathrm{t}-1)} * \mathrm{P}$

Where:

MK $(t)=$ Market share in period $t$

MK (t-1) $=$ Market share in the initial period

$\mathrm{P}=$ Transition Probability

The above equation shows the calculation of market share prediction in the coming period by multiplying the initial market share with the transition opportunity (Siagian, 2006). 


\section{Result And Discussion}

\subsection{Characteristics of Respondents}

Characteristics of respondents include socioeconomic characteristics consisting of age, education status, and income. The following table describes some of these characteristics.

Table 2. Characteristics of Respondents.

\begin{tabular}{lrr}
\hline \multicolumn{1}{c}{ Description } & Amount & Frequency (\%) \\
\hline Age Group & & \\
\hline $25-29$ & 20 & 4.5 \\
\hline $30-34$ & 18 & 13.7 \\
\hline $35-39$ & 30 & 12.3 \\
\hline $40-44$ & 30 & 20.5 \\
\hline $45-49$ & 26 & 20.5 \\
\hline $50-55$ & 14 & 18.0 \\
\hline$>55$ & 146 & 9.6 \\
\hline \multicolumn{1}{c}{ Amount } & & 100 \\
\hline Educational status & - & - \\
\hline Primary School & 6 & 4.1 \\
\hline JHS & 60 & 41.1 \\
\hline SHS & 28 & 19.2 \\
\hline Diploma & 52 & 34.6 \\
\hline Bachelor & 146 & 100 \\
\hline Amount & & \\
\hline Family Income & 32 & \\
\hline 2,000,000- & & \\
3,000,000 & 66 & 32.9 \\
\hline $3,000.001-$ & & 100 \\
\hline 4000,000 & 146 & \\
\hline$>4.000 .001$ & & \\
\hline \multicolumn{1}{c}{ Amount } & & \\
\hline
\end{tabular}

Table 2 shows that the age range of the highest respondent is $40-44$, and $45-49$ $(20.5 \%)$, then the age range $50-54(18.0 \%)$. This data explains that most respondents have long been married so in making decisions many things to consider. The previous table describes the highest education status of respondents is SHS (41.1\%), Bachelor (35.6\%), and Diploma (19.2\%). The data explains that respondents are more selective and rational in deciding to purchase cooking oil. Based on the above table it can be seen that the most significant amount of respondent income is in the range 3,000,000-4,000,000 (45.2\%), then $\geq$ $4,000,000(32.9 \%)$. The data shows that the income of respondents is high.

\subsection{Pattern of Redemption Brand of Cooking Oil}

The switch of the brand by the consumer will result in the pattern of switching the cooking oil brands to other brands, so please know the data acquisition of each consumer of real cooking oil. Information on current and past consumer numbers ( $\leq$ one year ago) are presented in the following table. 
Table 3. Number of Consumers Current and Past.

\begin{tabular}{lcccc}
\hline \multicolumn{1}{c}{ Brand } & Past & New & Switch & Current \\
\hline Bimoli & 58 & 34 & 38 & 54 \\
\hline Tropical & 16 & 38 & 12 & 41 \\
\hline Sania & 14 & 16 & 8 & 22 \\
\hline Filma & 10 & 6 & 4 & 12 \\
\hline Sunco & 16 & 4 & 26 & 10 \\
\hline Other & 16 & 12 & 32 & 12 \\
\hline Total & 146 & 104 & 104 & 146 \\
\hline
\end{tabular}

In addition to consumers who increase from other brands, the following are also presented consumers who switch to other brands on various cooking oil brands can be seen in the following table.

Table 4. Consumers who switch to other brands in different cooking oil brands.

\begin{tabular}{lllllll}
\hline Brand & \multicolumn{7}{c}{ Addition of other brands } \\
\hline & Bimoli & Tropical & Sania & Filma & Sunco & Other \\
\hline Bimoli & & 16 & 10 & 4 & 4 & 4 \\
\hline Tropical & 8 & & 4 & 0 & 0 & 0 \\
\hline Sania & 6 & 2 & & 0 & 0 & 0 \\
\hline Filma & 2 & 2 & 0 & & 0 & 0 \\
\hline Sunco & 8 & 14 & 0 & 2 & & 2 \\
\hline Other & 10 & 4 & 2 & 0 & 0 & \\
\hline Total & 34 & 38 & 16 & 6 & 4 & 6 \\
\hline \multicolumn{7}{c}{ Switched to other brands } \\
\hline \multicolumn{7}{c}{}
\end{tabular}

Table 3 and 4 show a pattern of brand displacement of cooking oil (Brand Switching Pattern) conducted by consumers. Brand Switching Pattern can be seen in the following table.

Table 5. Brand Switching Pattern.

\begin{tabular}{|c|c|c|c|c|c|c|c|c|}
\hline \multirow{8}{*}{$\begin{array}{c}\text { Fro } \\
\mathrm{m}\end{array}$} & \multirow[t]{2}{*}{ Brand } & \multicolumn{7}{|c|}{ To } \\
\hline & & Bimoli & $\begin{array}{c}\text { Tropica } \\
\text { l }\end{array}$ & $\begin{array}{c}\text { Sani } \\
\mathbf{a}\end{array}$ & Filma & Sunco & $\begin{array}{c}\text { Othe } \\
\mathbf{r}\end{array}$ & Past \\
\hline & Bimoli & 20 & 16 & 10 & 4 & 4 & 4 & 58 \\
\hline & $\begin{array}{l}\text { Tropica } \\
1\end{array}$ & 8 & 4 & 4 & 0 & 0 & 0 & 16 \\
\hline & Sania & 6 & 2 & 6 & 0 & 0 & 0 & 14 \\
\hline & Filma & 2 & 2 & 0 & 6 & 0 & 0 & 10 \\
\hline & Sunco & 8 & 14 & 0 & 2 & 6 & 2 & 32 \\
\hline & Other & 10 & 4 & 2 & 0 & 0 & 0 & 16 \\
\hline \multicolumn{2}{|c|}{ Current } & 54 & 42 & 22 & 12 & 10 & 6 & 146 \\
\hline
\end{tabular}

\subsection{Reasons for Consumers Choosing and Switching Brand}

Based on the distribution of questionnaires to 146 homemakers throughout Medan, the brand information obtained from cooking oil consumed by consumers describes in the following table. 
Table 6. Cooking Oil Brands and Number of Consumers.

\begin{tabular}{lrr}
\hline \multicolumn{1}{c}{ Brand } & Current & Proporsition \\
\hline Bimoli & 54 & $37 \%$ \\
\hline Tropical & 42 & $28.7 \%$ \\
\hline Sania & 22 & $15.1 \%$ \\
\hline Filma & 12 & $8.2 \%$ \\
\hline Sunco & 19 & $6.8 \%$ \\
\hline Lain & 6 & $4.2 \%$ \\
\hline Total & 146 & $100 \%$ \\
\hline
\end{tabular}

The consumer's reason for choosing and switching the cooking oil brands are presented in the following tables.

Table 7. Consumer's reason fo choose the cooking oil brand.

\begin{tabular}{lrrrrrr}
\hline \multicolumn{1}{c}{ Reason } & \multicolumn{7}{c}{ Brand } \\
\cline { 2 - 8 } & Bimoli & Tropical & Sania & Filma & Sunco & Other \\
\hline Low price & 8 & 22 & 4 & - & 6 & 6 \\
\hline The color of cooking oil & 2 & 4 & - & - & - & - \\
\hline Top rated products & 12 & 2 & 8 & - & 2 & - \\
\hline Filtering process & - & - & 2 & 8 & - & - \\
\hline The packaging is interesting & - & - & - & - & - & - \\
\hline Easily obtained & 12 & 2 & - & - & - & - \\
\hline Information on nutritional value & 8 & 6 & 8 & 4 & 2 & - \\
\hline The taste of cuisine is tastier & - & 6 & - & - & - & - \\
\hline Habits of the family & 12 & - & - & - & - & - \\
\hline \multicolumn{1}{c}{ Total } & 54 & 42 & 22 & 12 & 10 & 6 \\
\hline
\end{tabular}

The behavior of brand switching to the customer is a complex phenomenon that is influenced by many factors such as consumer dissatisfaction, behavior, competition, and price. Consumer switching brand can also be caused by variations seeking that are influenced by sales promotion and advertising. The reason why consumers switch to other brands is presented in the following table.

Table 8. Consumer's reason switch to cooking oil brand.

\begin{tabular}{|c|c|c|}
\hline Reasons & Qty & $\%$ \\
\hline Only try & 42 & 40.3 \\
\hline Friend suggestions & 10 & 9.6 \\
\hline Ads and Promotions & 8 & 7.6 \\
\hline Discount & 20 & 19.2 \\
\hline Unsatisfied after used & 14 & 13.4 \\
\hline Total & 104 & 100 \\
\hline
\end{tabular}

\subsection{Market Share Analysis of Current Cooking Oil}

Based on the results of data processing, the authors obtained information on the amount of initial market share by each cooking oil brands. Table 8 describes the size and market share 
of each cooking oil brands. Then this initial market share is used as a reference for further calculations. The initial market share of cooking oil brands is presented in the following table.

Table 9. Market Share of Current Cooking Oil.

\begin{tabular}{lrr}
\hline Brand & Current & Market Share \\
\hline Bimoli & 54 & $37 \%$ \\
\hline Tropical & 42 & $28.7 \%$ \\
\hline Sania & 12 & $15.1 \%$ \\
\hline Filma & 19 & $8.2 \%$ \\
\hline Sunco & 22 & $6.8 \%$ \\
\hline Other & 6 & $4.2 \%$ \\
\hline Total & 146 & $100 \%$ \\
\hline
\end{tabular}

\subsection{Predicted Market Share of Cooking Oil with Markov Chain}

It is a method that studies the properties of a variable in the present based on the past traits as an effort to assess the properties of those variables in the future. In Markov's analysis, the result is probabilistic information that can be used to assist decision-making, this analysis is not an optimization technique but a descriptive technique. The assumptions in the Markov Chain relate to the transitional state which is as follows:

- The number of state transition probabilities is 1

- The transition probability does not change forever

- The transition probability depends only on the current status, not the period

The calculation of transition probabilities is presented in the following table.

. Table 10. Probability of Brand Switching of Cooking Oil.

\begin{tabular}{|c|c|c|c|c|c|c|c|}
\hline \multirow[t]{8}{*}{ From } & \multirow[t]{2}{*}{ Brand } & \multicolumn{6}{|c|}{ To } \\
\hline & & Bimoli & Tropical & Sania & Filma & Sunco & Other \\
\hline & Bimoli & 0.34 & 0.28 & 0.17 & 0.07 & 0.07 & 0,07 \\
\hline & Tropical & 0.50 & 0.25 & 0.25 & 0 & 0 & 0 \\
\hline & Sania & 0.43 & 0.14 & 0.43 & 0 & 0 & 0 \\
\hline & Filma & 0.20 & 0.20 & 0 & 0.60 & 0 & 0 \\
\hline & Sunco & 0.25 & 0.44 & 0 & 0.06 & 0.19 & 0,06 \\
\hline & Other & 0.63 & 0.25 & 0.12 & 0 & 0 & 0 \\
\hline Mal & Share & 0.37 & 0.29 & 0.15 & 0.08 & 0.07 & 0.04 \\
\hline
\end{tabular}

The prior transition probability is used as a transition probability matrix which is then symbolized by $\mathrm{P}$ while the above Market Share row is referred to as the initial market share symbolized by $\mathrm{MK}(0)$. MK (t-1) * $\mathrm{P}$ is to calculate market share predictions in the future period or by multiplying market share in the first period with a transition probability matrix. Based on Table 9, it is known that MK (0) and transition probability matrix P are as follows:

$$
M K(0)=\left[\begin{array}{llllll}
0.37 & 0.29 & 0.15 & 0.08 & 0.07 & 0.04
\end{array}\right]
$$




$$
P=\left[\begin{array}{cccccc}
0.37 & 0.28 & 0.17 & 0.07 & 0.07 & 0.07 \\
0.50 & 0.25 & 0.25 & 0 & 0 & 0 \\
0.43 & 0.14 & 0.43 & 0 & 0 & 0 \\
0.20 & 0.20 & 0 & 0.60 & 0 & 0 \\
0.25 & 0.44 & 0 & 0.06 & 0.19 & 0.06 \\
0.63 & 0.25 & 0.12 & 0 & 0 & 0
\end{array}\right]
$$

The following values are the predicted market share of cooking oil products in the second and third period.

$$
\begin{aligned}
M K(1) & =M K(0) * P \\
M K(1) & =\left[\begin{array}{llllll}
0.394 & 0.254 & 0.205 & 0.077 & 0.039 & 0.030
\end{array}\right] \\
M K(2) & =M K(1) * P \\
M K(2) & =\left[\begin{array}{llllll}
0.393 & 0.243 & 0.223 & 0.076 & 0.036 & 0.029
\end{array}\right]
\end{aligned}
$$

Based on the above calculation, the prediction of market share for three periods on various of cooking oil brands consumed by consumers in Medan is determined. Predicted market share in the first, second and third periods for each cooking oil brands are illustrated in the following table.

Table 11. Market Share Prediction Upcoming Years.

\begin{tabular}{lllll}
\hline Brand & Current & Period 1 & Period 2-3 & Average \\
\hline Bimoli & $37.00 \%$ & $39.40 \%$ & $39.30 \%$ & $38.57 \%$ \\
\hline Tropical & $29.00 \%$ & $24.10 \%$ & $24.30 \%$ & $26.23 \%$ \\
\hline Sania & $15.00 \%$ & $20.50 \%$ & $22.30 \%$ & $19.27 \%$ \\
\hline Filma & $8.00 \%$ & $7.70 \%$ & $7.60 \%$ & $7.77 \%$ \\
\hline Sunco & $7.00 \%$ & $3.90 \%$ & $3.60 \%$ & $4.83 \%$ \\
\hline Other & $4.00 \%$ & $3.00 \%$ & $2.90 \%$ & $3.30 \%$ \\
\hline Total & $100 \%$ & $100 \%$ & $100 \%$ & $100 \%$ \\
\hline
\end{tabular}

\section{Conclusion}

This study explains the pattern of switching cooking oil brands from one brand to another made by homemakers. Consumers who switched to the Tropical and Sania were more comparable to consumers who moved from both brands. The number of consumers who move from Bimoli, Filma, Sunco, and other brands such as Fortune and Kunci Mas, more than consumers who switch to these brands. Most consumers choose Bimoli since it is a familiar or a well-known product. Furthermore, consumers who choose Tropical is mostly due to the price is low while consumers choose Sania is due to the most information about the value of nutrition. The reason consumers choose the Filma is due to the screening process. An overview of the reasons consumers switch cooking oil brand is merely trying or needing to find another variation of 40.3 percent. Furthermore, there is a 19.2 percent discount stimulus and unsatisfied with using 13.4 percent. Bimoli cooking oil market share is 39.4 percent for the upcoming year, Tropical Brands 24.1 percent and Sania 20.5 percent. All three brands will dominate 84 percent of the packaged cooking oil brand market. As for the next two years, the market share of Bimoli is 39.3 percent, Tropical Brands 24.3 percent and Sania 22.3 percent.

\section{Future Scope}

The authors suggest to manufacturers of cooking oil brands to highlight the attributes and products characteristics so that consumers can remember the brand in their minds. The reason 
consumers who move most brands because they want to try the brand. It indicates an opportunity for brands outside Bimoli, Tropical, Sania to try to erode the consumer market. For further research, it is advisable to develop the indicators, research models to enable other researchers to develop the Markov Chain and other models.

\section{Acknowledgements}

The authors gratefully acknowledge the financial support from Universitas Pembangunan Panca Budi, and we would like to thank the reviewers for guidance sincerely.

\section{References}

[1] Aaker, D. A. (1997) Manajemen ekuitas merek. Jakarta: Sapektrum.

[2] Durianto and Sitinjak. (2001) Strategi Menaklukkan Pasar Melalui. Riset Ekuitas dan Perilaku Merek. Jakarta: PT. Gramedia Pustaka.

[3] Engel, et. all. (2000) 'Consumer Behavior, 8th ed. Orlando. The Dryden Press'.

[4] Kotler, P. (2001) Manajemen Pemasaran. Edisi VII. Jakarta: FE-UI Press.

[5] Siagian, P. (2006) Penelitian Operasional. Jakarta: UI-Press. 